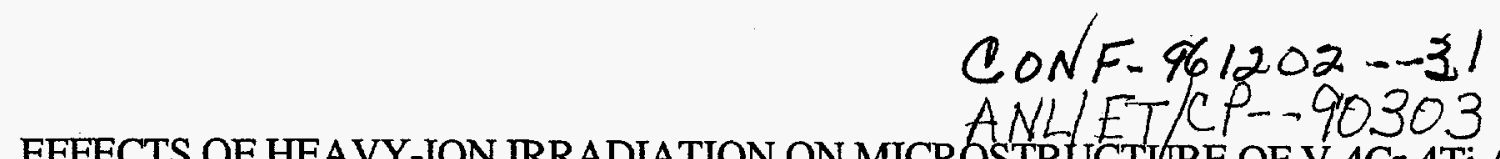

EFFECTS OF HEAVY-ION IRRADIATION ON MICROSTRUCTURE OF V-4Cr-4Ti ALLOY AT MODERATE TEMPERATURES*

RECEIVED

JAN 161997

OSTI
J. Gazda and M. Meshii

Materials Science and Engineering Dept.

Northwestern University

2525 N. Campus Dr.

Evanston IL 60208
H. M. Chung, and B. A. Loomis**

Argonne National Laboratory

9700 S. Cass Ave.

Argonne IL 60439

December 1, 1996

The submitted manuscript has been authored

by a contractor of the U.S. Government under

contract No. W-31-109-ENG-38.

Accordingly, the U.S. Government retains a

nonexclusive, royalty-free license to publish

or reproduce the published form of this

contribution, or allow others to do so, for U.S.

Government purposes.

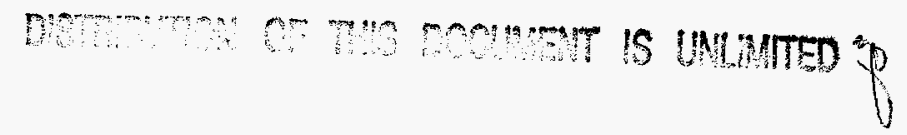

To be submitted to: Symposium B, Microstructure Evolution During Irradiation, at MRS Fall Mtg., December 1-5, 1996, Boston MA.

"Work supported by the Office of Fusion Energy, U.S. Department of Energy, under Contract W-31-109-Eng-38.

* Deceased in 1996 


\section{DISCLAIMER}

Portions of this document may be illegible in electronic image products. Images are produced from the best available original document. 


\title{
EFFECTS OF HEAVY-ION IRRADIATION ON MICROSTRUCTURE OF V-4Cr-4Ti ALLOY AT MODERATE TEMPERATURES*
}

\author{
J. Gazda, ${ }^{1,2}$ H. M. Chung, ${ }^{2}$ B. A. Loomis, ${ }^{2, * *}$ and M. Meshii ${ }^{1}$ \\ ${ }^{1}$ Northwestern University, Dept. of M.S.\&E., Evanston, IL \\ ${ }^{2}$ Argonne National Laboratory, Energy Tech Div., Argonne, IL
}

\begin{abstract}
$\mathrm{V}-4$ wt.\% $\mathrm{Cr}-4$ wt.\% $\mathrm{Ti}$ alloy is a promising candidate material for first-wall and structural applications in magnetic fusion reactors. In the past, fast neutron sources were used to evaluate postirradiation properties of fusion candidate materials. The recent shutdowns of the Fast Flux Test Facility (FFTF) and the Experimental Breeder Reactor (EBR-II) left U.S. researchers without local experimental facilities for such tests. Under such circumstances, ease of experimental control, availability, and relatively low cost make heavy-ion irradiation an attractive alternative, provided its limitations are appreciated. We selected $3-\mathrm{MeV} \mathrm{V}^{+}$and $4.5-\mathrm{MeV} \mathrm{Ni}^{++}$ions to investigate the effects of irradiation on the microstructure of $\mathrm{V}-4 \mathrm{Cr}-4 \mathrm{Ti}$ alloy in the temperature range of $200-420^{\circ} \mathrm{C}$. The main interest is in the evaluation of this alloy's dimensional stability and susceptibility to irradiation embrittlement. In this paper, we report results of ion irradiation experiments and compare them with available data on fast-neutron irradiation. From transmission electron microscopy (TEM) analysis of ion-irradiated specimens, we found that the dominant feature of the postirradiation microstructure was a high density of dislocation loops and pointdefect clusters. Density and defect size depended on irradiation dose and temperature. Precipitates and voids/bubbles were not observed, even in specimens that were simultaneously injected with $\mathrm{He}$ and exposed to heavy-ion irradiation. Increased transport of point defects to internal interfaces was observed, as manifested by defect denuded zones along grain boundaries, Defect denuded zones along grain boundaries could lead to segregation of impurities and solutes and formation of precipitates on grain boundaries.
\end{abstract}

\section{INTRODUCTION}

Vanadium-base alloys are promising candidate materials for application in fusion reactors. Their advantage over other candidate alloys stems from their low intrinsic neutron activation, compatibility with $\mathrm{Li}$ reactor coolant, and refractory nature. ${ }^{1,2}$ Results from past neutron irradiation experiments show that V-base alloys can be tailored to sustain higher operating temperature, stress, and neutron fluence than stainless steels, without suffering embrittlement or significant dimensional changes (swelling). ${ }^{3}$ These experiments were performed at temperatures above $420^{\circ} \mathrm{C}$. Recent consideration of V-base alloys for applications as first-wall and structural material in the International Thermonuclear Experimental Reactor ( ITER ) prompted evaluation of the irradiation performance of these alloys in the temperature range from 200 to $420^{\circ} \mathrm{C}$, which is also relevant to transient situations in other fusion reactors.

Because operational fusion reactors are not available, the standard procedure to evaluate irradiation performance of materials that are relevant to a fusion environment is to perform irradiation experiments in fast-neutron spectra $\left(E_{n}>0.1 \mathrm{MeV}\right)$. In the past, the widely used devices were the 14-MeV Rotating Target Neutron Source RTNS and fast-fission reactors: i.e., the Fast Flux Test Facility FFTF and the Experimental Breeder Reactor EBR-II. However, these facilities are no longer available. The recent shutdown of EBR-II (September 1994) left U.S. experimenters without access to a local fast reactor. At this time, evaluation of the irradiation behavior of materials is limited to irradiation in mixed-neutron-spectrum reactors ${ }^{4,5}$ (with their inherited excessive transmutations due to thermal neutrons), or to conducting experiments in foreign facilities $^{6}$ (which extend costs and experimental time). In such a predicament, the ease of experi-

\footnotetext{
*Work supported by the Office of Fusion Energy, U.S. Department of Energy, under Contract W-31-109-Eng-38.

** Deceased in 1996.
} 
mental control, availability, and relatively low cost make heavy-ion irradiation an attractive alternative or supplement, provided its limitations are appreciated. The limitations include inhomogeneous profile of damage, small volume of irradiated material, different recoil spectrum than that of neutrons, and changes in target composition that are a result of atom injection. The main advantages of ion irradiation arise from the ease of experimental control (temperature, fluence, and dose rate), wide availability of irradiation facilities, relatively low cost, and, in some facilities, possibility of in situ studies. ${ }^{7}$

From the family of V-base alloys, the $\mathrm{V}-4 \mathrm{wt} . \% \mathrm{Cr}-4 \mathrm{wt} \% \mathrm{Ti}$ (V4Cr4Ti) composition gives superior irradiation performance. ${ }^{8}$ We selected $3-\mathrm{MeV} \mathrm{V}^{+}$and $4.5-\mathrm{MeV} \mathrm{Ni}^{++}$ions to investigate the effects of irradiation on the microstructure of $\mathrm{V} 4 \mathrm{Cr} 4 \mathrm{Ti}$ alloy in the temperature range of 200$420^{\circ} \mathrm{C}$. Microstructure was observed by transmission electron microscopy (TEM). The main interest is to evaluate this alloy's dimensional stability and susceptibility to irradiation embrittlement. In this article, we report on the progress of ion irradiation experiments and present limited, preliminary, TEM data that is available from the EBR-II X530 fast-neutron irradiation experiment conducted at $\approx 370^{\circ} \mathrm{C}$.

\section{EXPERIMENTS}

Procedures used to prepare the V4Cr4Ti alloy (Heat 832665, ANL ID BL71) have been described in detail elsewhere.' Composition of the alloy is given in Table $I$. The plate used to prepare TEM specimens for irradiation experiments was warm rolled (at $400^{\circ} \mathrm{C}$ ) to a thickness of 1 $\mathrm{mm}$ and then cold rolled at room temperature to $250 \mu \mathrm{m}$. Standard 3-mm-diameter discs were punched from the $250-\mu \mathrm{m}$-thick sheet. Discs used for ion irradiation were ground to a thickness of $\approx 125 \mathrm{~mm}$ thickness before polishing and annealing. All discs were mechanically polished to a $0.050-\mu \mathrm{m}$ surface finish and annealed in a UHV ion pumped furnace $\left(<10^{-5} \mathrm{~Pa}\right)$ for $1 \mathrm{~h}$ at $1050^{\circ} \mathrm{C}$ (for ion irradiations) or $1125^{\circ} \mathrm{C}$ (for neutron irradiations). The result was a fully recrystallized material with an average grain size of $20-40 \mu \mathrm{m}$.

Table I. Composition (impurities in wppm) of V-4Cr-4Ti alloy (Heat 832665, BL71)

\begin{tabular}{ccccccccccccc}
\hline ANL ID & $\mathrm{Cr}$ & $\mathrm{Ti}$ & $\mathrm{Cu}$ & $\mathrm{Si}$ & $\mathrm{O}$ & $\mathrm{N}$ & $\mathrm{C}$ & $\mathrm{S}$ & $\mathrm{P}$ & $\mathrm{Ca}$ & $\mathrm{Cl}$ & $\mathrm{B}$ \\
\hline $\mathrm{BL}-71$ & $3.8 \mathrm{wt} \%$ & $3.9 \mathrm{wt} \%$ & $<50$ & 783 & 310 & 85 & 80 & $<10$ & $<30$ & $<10$ & $<2$ & $<5$ \\
\hline
\end{tabular}

Ion irradiations were performed at the Argonne Tandem Accelerator facility operated by the Materials Science Division. Beams of $4.5-\mathrm{MeV} \mathrm{Ni}^{++}$and $3-\mathrm{MeV} \mathrm{V}^{+}$ions were produced by a 2MV NEC ion accelerator. During some irradiation runs, He was simultaneously injected into specimens at the rate of $5 \mathrm{appm} / \mathrm{dpa}$ by means of $0.35-\mathrm{MeV} \mathrm{He} \mathrm{H}^{+}$ion beams from the $0.65-\mathrm{MV}$ NEC ion implanter. Vacuum in the irradiation chamber was maintained at $1 \cdot 10^{-6} \mathrm{~Pa}$. Separate ion irradiation runs were performed with specimens kept within $\pm 2^{\circ} \mathrm{C}$ at 200,350 , and $420^{\circ} \mathrm{C}$. TEM foils were prepared by removing an 800 -nm-thick section from the irradiated surface and backthinning specimens to electron transparency. The $800-\mathrm{nm}$ depth was selected on the basis of TRIM Code (version 95$)^{10}$ simulations of ion deposition ranges and damage profiles. TEM foils allowed observation of regions with highest $\mathrm{He}$ and $\mathrm{V}$ atom deposition rate, sufficient irradiation damage rates, and insignificant $\mathrm{Ni}$ deposition.

Neutron irradiations were completed during the last run of the EBR-II reactor in August/September 1994. The details of this irradiation experiment and the specimen matrix are given in an earlier report. ${ }^{11}$ Specimens were irradiated in Li-filled capsules for 35 full-power days at $\approx 370-390^{\circ} \mathrm{C}$ in core position (flux of $2.4 \cdot 10^{15} \mathrm{n} \cdot \mathrm{cm}^{-2} \cdot \mathrm{s}^{-1}, \mathrm{E}>0.11 \mathrm{MeV}$ ), and attained a damage dose of $\approx 4 \mathrm{dpa}$. TEM discs used for the present work were randomly selected from a batch annealed at $1125^{\circ} \mathrm{C}$. Discs were electropolished from both sides to electron transparency to avoid near-surface regions. Electropolishing of all irradiated TEM discs was accomplished with a South Bay Technology Single Jet Electropolisher 550B and electrolyte consisting of, by volume, $70 \%$ $\mathrm{H}_{2} \mathrm{SO}_{4}, 15 \% \mathrm{CH}_{3} \mathrm{OH}$, and $15 \% \mathrm{C}_{6} \mathrm{H}_{14} \mathrm{O}_{2}$ Butyl Cellosolve that was maintained near $-10^{\circ} \mathrm{C}$.

TEM observations were performed with two transmission electron microscopes. The microstructure of ion-irradiated specimens were evaluated with a Phillips CM30 analytical TEM. Neutron-irradiated specimens were examined using a JEOL 100CX TEM equipped with thick window X-ray energy dispersive spectrometer X-EDS, in which work with radioactive materials is allowed. The size and number density of radiation-produced defects were measured with a Zeiss particle size analyzer/counter from prints of electron-micrographs that were obtained from foils of 
known thickness. Foil thickness was measured by electron energy loss analysis, calibrated by stereomicroscopy and foil tilting experiments.

\section{RESULTS}

The typical microstructure of ion-irradiated $\mathrm{V} 4 \mathrm{Cr} 4 \mathrm{Ti}$ at all temperatures consisted of a high density of "black dot" defect clusters and dislocation loops, on the order of $2 \cdot 10^{22} \mathrm{~m}^{-3}$. Short dislocation segments were occasionally observed at $420^{\circ} \mathrm{C}$ and $10 \mathrm{dpa}$. Two types of dislocation Burgers vectors, $a_{0}<100>$ and $a_{0} / 2<111>$, were observed, with the latter one predominating. The typical microstructural evolution with increasing damage dose $(0.5$ to $5 \mathrm{dpa})$ at constant temperature $\left(200^{\circ} \mathrm{C}\right)$ is shown in Fig 1 . The effects of temperature $\left(200-420^{\circ} \mathrm{C}\right)$ on the size of the dislocation loops and their number density is shown in Fig. 2 for specimens irradiated to 0.5 dpa. Examples of microstructure after irradiation at $350^{\circ} \mathrm{C}$ to $5 \mathrm{dpa}$ with/without $\mathrm{He}$ are shown in Fig.

3. The effects of simultaneous He injection during ion irradiation were insignificant.

For comparison with irradiated specimens, Fig. 4 shows the typical microstructure of V4Cr4Ti alloy after aging in the irradiation chamber during a typical ion irradiation run, i.e., $8 \mathrm{~h}$ at $420^{\circ} \mathrm{C}$ in $10^{-6} \mathrm{~Pa}$ vacuum. The microstructure is identical to that of the as-annealed material.

Most of the ion irradiations were performed with $\mathrm{Ni}^{++}$ions. To determine the effects of $\mathrm{Ni}$, if

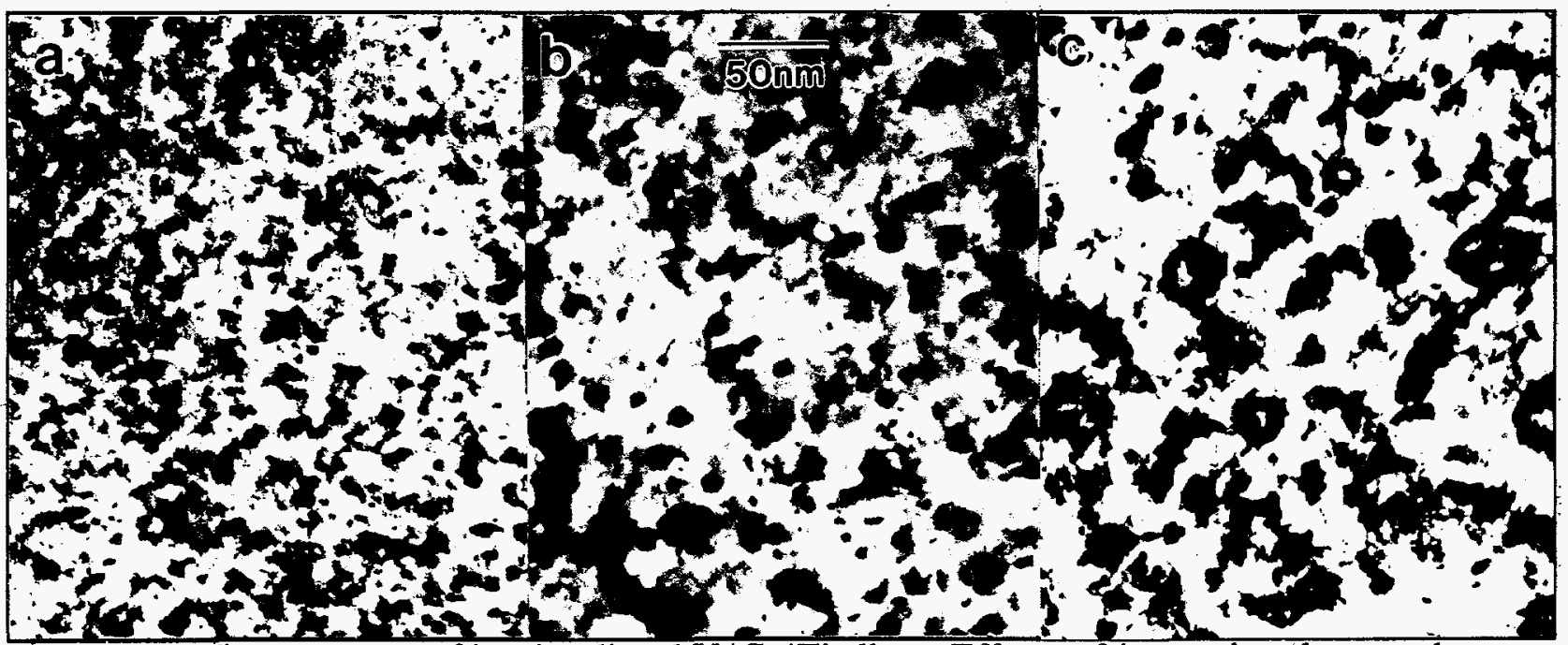

Figure 1. Microstructure of ion-irradiated V4Cr4Ti alloy. Effects of increasing damage dose at $200^{\circ} \mathrm{C}$; (a) 0.5 , (b) 2 , and (c) $5 \mathrm{dpa}$. Defects imaged in dynamical two-beam condition with $\mathrm{g}=$ (01-1) near [011] foil orientation.

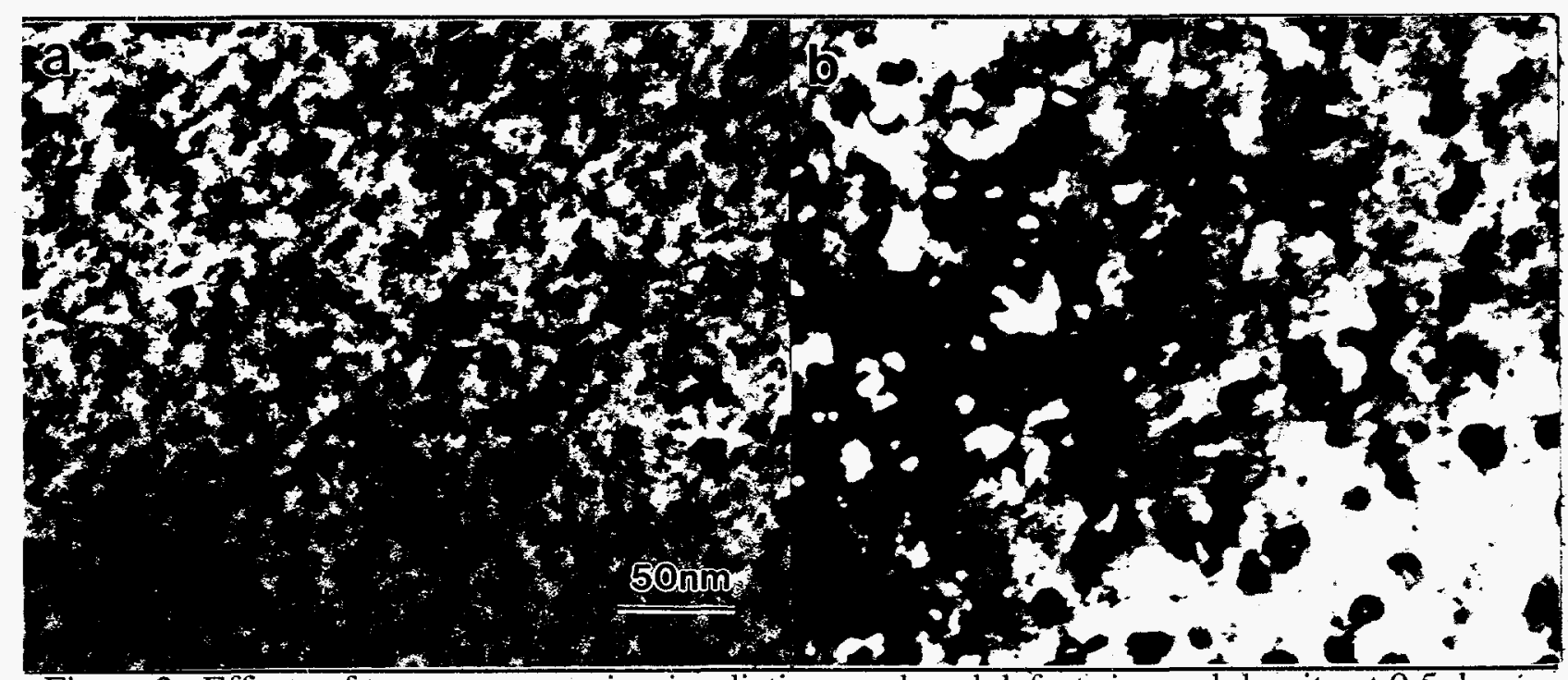

Figure 2. Effects of temperature on ion-irradiation-produced defect size and density at $0.5 \mathrm{dpa}$, (a) $200^{\circ} \mathrm{C}$, foil thickness $\approx 50 \mathrm{~nm}$, and (b) $420^{\circ} \mathrm{C}$, foil thickness $\approx 60 \mathrm{~nm}$. 


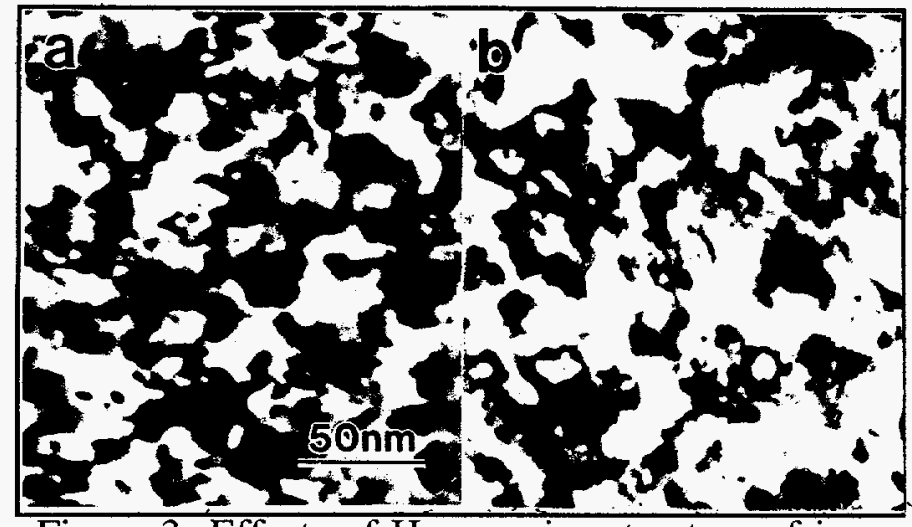

Figure 3. Effects of He on microstructure of ionirradiated $\mathrm{V} 4 \mathrm{Cr} 4 \mathrm{Ti}, 5 \mathrm{dpa}$ at $350^{\circ} \mathrm{C}$; (a) without $\mathrm{He}$, (b) 25 appm of He injected.

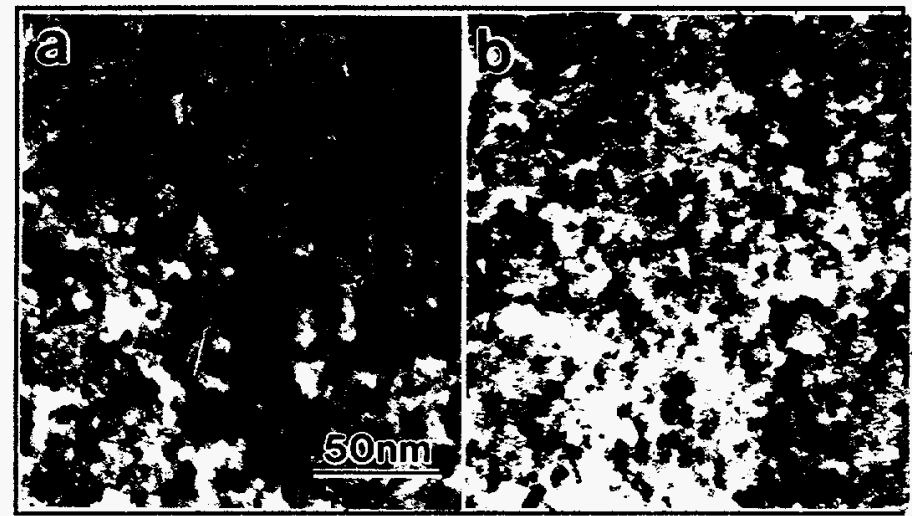

Figure 5. Lack of effects of $\mathrm{Ni}$ on microstructure produced by ion irradiation at $200^{\circ} \mathrm{C}$ to $0.5 \mathrm{dpa}$; (a) $\mathrm{Ni}^{++}$, and (b) $\mathrm{V}^{+}$

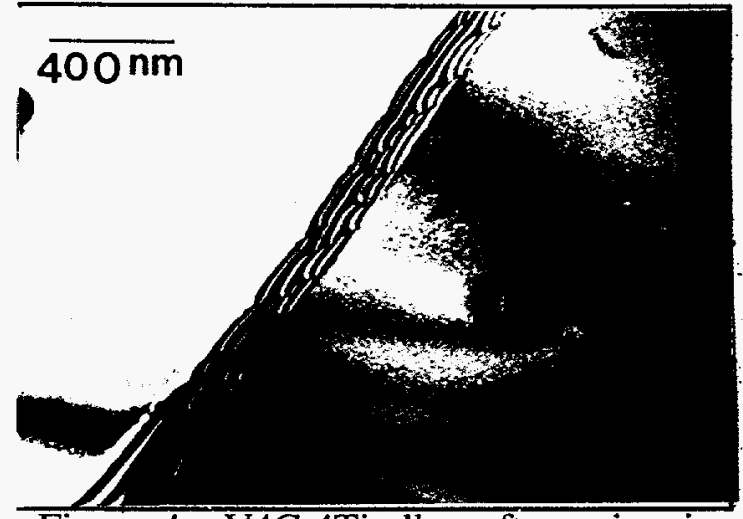

Figure 4. V4Cr4Ti alloy after aging in irradiation chamber for $8 \mathrm{~h}$ at $420^{\circ} \mathrm{C}$, in $10^{-5} \mathrm{~Pa} \mathrm{UHV}$ vacuum.

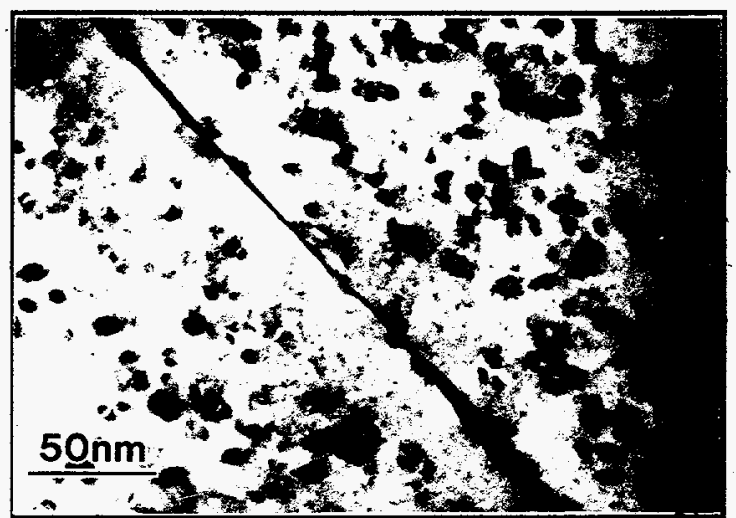

Figure 6. Defect-denuded zones near grain boundary of $\mathrm{V} 4 \mathrm{Cr} 4 \mathrm{Ti}$ alloy irradiated at $420^{\circ} \mathrm{C}$ to $0.5 \mathrm{dpa}$.

any, a limited number of irradiations were carried out with $3-\mathrm{MeV} \mathrm{V}^{+}$ions. Figure 5 shows microstructures produced by both types of ions at $200^{\circ} \mathrm{C}$ and $0.5 \mathrm{dpa}$. No difference in defect structure was observed.

Increased transport of point defects to preexisting dislocations, grain boundaries and precipitate/matrix interfaces was documented in ion-irradiated specimens. Defect-denuded zones, $\approx 100 \mathrm{~nm}$ wide, were most pronounced along grain boundaries and precipitate/matrix interfaces at $420^{\circ} \mathrm{C}$, but were also present in specimens irradiated at $350^{\circ} \mathrm{C}$ (width $\approx 40 \mathrm{~nm}$ ). An example is

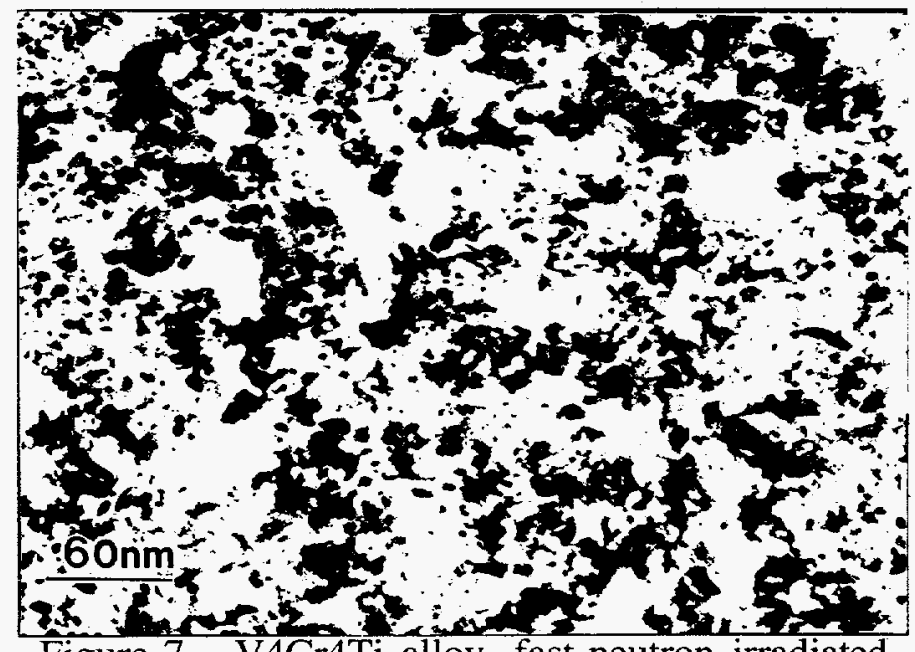

Figure 7. V4Cr4Ti alloy, fast-neutron irradiated to 4 dpa at $\approx 385^{\circ} \mathrm{C}$. $\mathrm{g}=(01-1)$ near [011].

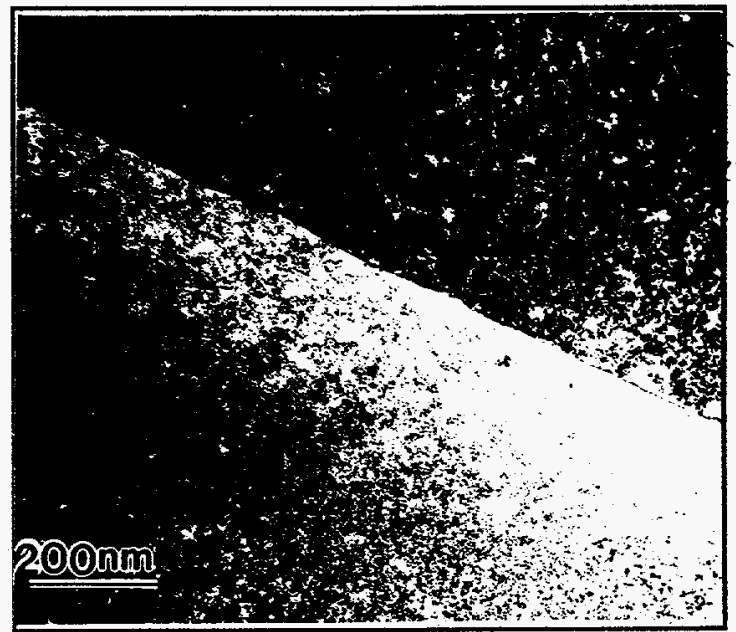

Figure 8. Grain boundary region in V4Cr4Ti alloy; fast-neutron irradiated to 4 dpa at $\approx 385^{\circ} \mathrm{C}$. 
given in Fig. 6. Formation of denuded zones was accompanied by an increase in size, number of grain boundary precipitates, and in some cases formation of a nearly continuous film on the grain boundaries. High Ti content was detected in the grain boundary phase by X-EDS analysis, but phase identification of precipitates has not yet been completed. Increased counts in the Ti/V/Cr Lline energy range, which coincide with $\mathrm{O}$ and $\mathrm{N} \mathrm{K}$-line energies, were observed. Lack of evidence for the presence of any other elements in the grain boundary film leads us to suspect that the phase may be a combination of Ti and scavenged interstitial impurities $(\mathrm{C}, \mathrm{N}, \mathrm{O})$.

For comparison purposes, a typical microstructure of $\mathrm{V} 4 \mathrm{Cr} 4 \mathrm{Ti}$ alloy, neutron-irradiated to 4 dpa at $\approx 385^{\circ} \mathrm{C}$, is shown in Fig. 7. In preliminary work, we observed a high density of black dots and dislocation loops in sizes and number density comparable to those that are a result of ion irradiation (on the order of $10^{22} \mathrm{~m}^{-3}$ ). Similarly to the ion-irradiated material, neutron-irradiated $\mathrm{V} 4 \mathrm{Cr} 4 \mathrm{Ti}$ formed a grain boundary phase; however, the number density of grain boundary precipitates was lower and defect-denuded zones were not observed. Figure 8 shows a typical grain boundary region in neutron-irradiated V4Cr4Ti.

\section{DISCUSSION}

During irradiation at moderate temperatures, the microstructure of $\mathrm{V} 4 \mathrm{Cr} 4 \mathrm{Ti}$ alloy evolves with increasing fluence. This process is exemplified in Fig. 1 for specimens that were irradiated at $200^{\circ} \mathrm{C}$. In the early stages $(\leq 0.5 \mathrm{dpa})$, defect clusters-'black dots' form with the number density reaching $\approx 2.5 \times 10^{22} \mathrm{~m}^{-3}$. The total number density of defects remains constant with increasing fluence $(\leq 5 \mathrm{dpa})$; however, the character and size of the defects changes. The microstructure at 0.5 dpa is characterized by nearly uniform distribution of point defect clusters with diameters near 4 $\mathrm{nm}$. At 2 dpa, dislocation loops with diameters ranging from 6 to $20 \mathrm{~nm}$ are resolvable and the black dots, with size remaining near $5 \mathrm{~nm}$, are still present. At $5 \mathrm{dpa}$, dislocation loops with diameters reaching up to $25 \mathrm{~nm}$ are prevailing, but the most commonly found diameter is $9 \mathrm{~nm}$. A still higher irradiation dose, $10 \mathrm{dpa}$, resulted in formation of short dislocation segments, loops with maximum diameters of $30 \mathrm{~nm}$, and point defect clusters with a mean diameter of $5 \mathrm{~nm}$. Increase of irradiation temperature accelerates the loop growth process, as illustrated in fig. 2 . At $420^{\circ} \mathrm{C}$, a 0.5 -dpa damage dose is sufficient to produce well developed dislocation loops the size of which increases at higher doses. The dislocation segments observed at $420^{\circ} \mathrm{C}$ and $10 \mathrm{dpa}$ appear to be formed by large dislocation loops that cut foil surfaces. The length of the segments was $\approx 50 \mathrm{~nm}$, comparable to the foil thickness and larger than the most of the loops observed in these specimens (diam. $\leq 25 \mathrm{~nm}$ ), which suggests that the large loops were formed by absorption of smaller dislocation loops.

Diffusion of point defects is responsible for cluster/loop distribution, as exemplified by formation of defect-denuded zones near grain boundaries. In pure $V$, self-interstitial atoms are free to migrate at temperatures above $8 \mathrm{~K}$, whereas vacancies start to migrate near $200 \mathrm{~K}$ and are quick to bind with interstitial impurities $(\mathrm{C}, \mathrm{N}, \mathrm{O})$, to become stationary clusters until temperature is increased to $\approx 450 \mathrm{~K}$, when these clusters dissociate. ${ }^{12}$ In V-base alloys, oversized $\mathrm{Ti}$ provides additional sinks for vacancies and increases the dissociation temperature of vacancy-Ti-impurity clusters. ${ }^{13,14}$ At the same time, the threshold temperature for free interstitial diffusion of $\mathrm{O}$ in pure $\mathrm{V}$ is $480 \mathrm{~K}$, and it is slightly higher for $\mathrm{C}$ and $\mathrm{N} .{ }^{12}$ The current ion irradiation experiments show uniform defect cluster distribution after irradiation at $473 \mathrm{~K}\left(200^{\circ} \mathrm{C}\right)$ and formation of $100 \mathrm{~nm}$ wide defect-denuded zones near preexisting sinks, combined with increase of Ti concentration on the grain boundaries at higher temperatures. The width of defect-free zones increases from $\approx 40 \mathrm{~nm}$ at $623 \mathrm{~K}\left(350^{\circ} \mathrm{C}\right)$ to $\approx 100 \mathrm{~nm}$ at $693 \mathrm{~K}\left(420^{\circ} \mathrm{C}\right)$. Radiation-enhanced diffusion of complexes that contain interstitial impurities and $\mathrm{Ti}$ atoms to vacancy sinks could explain the formation of the secondary phase on grain boundaries, a phenomenon that is not observed in the material aged at the same temperature.

Lack of the defect-free zones near grain boundaries of neutron-irradiated specimens is puzzling. If radiation-enhanced diffusion is responsible for defect-free zone formation, then the neutron-irradiated specimens should have wider defect-denuded zones than the ion-irradiated specimens; because their damage rate was lower, by three orders of magnitude, and the total irradiation time longer than these of the ion-irradiated specimens. Our observations were limited to three TEM foils prepared out of the neutron-irradiated material, therefore it is possible that we do not have a statistically reliable data, especially since the ion irradiations were performed in a UHV vacuum and neutron irradiations in Li filled capsules. This issue needs further investigation. 
Finally, the focus of this study was to determine the swelling and embrittlement potential of Vbase alloys that were irradiated at moderate temperatures. Voids were not observed in any of the irradiated specimens; therefore, swelling should not be considered a critical issue for irradiation at $200-420^{\circ} \mathrm{C}$, at least up to $10 \mathrm{dpa}$ fluence. However, embrittlement could become a limiting. Transmission electron microscopy observations can only provide microstructural data; they cannot directly measure mechanical properties. The observed formation of the grain boundary phase in irradiated specimens could lead to intergranular fracture, especially because recent work on crack propagation in V-base alloys, after fast-neutron irradiation at $600-800^{\circ} \mathrm{C}$ to $6.1 \mathrm{dpa}$, ${ }^{15}$ indicates that intergranular fracture could result from $\mathrm{He}$ and/or impurities $(\mathrm{C}, \mathrm{N}, \mathrm{O})$ accumulated on grain boundaries. Moreover, a high density of dislocation loops and defect clusters was observed in grain matrices. Presence of defect clusters usually does not lead to severe embrittlement, although it can increase the hardness of a material. However, if the clusters interact with impurities and/or alloying elements ( $\mathrm{Ti}$ ), such formed complexes could increase the yield strength of a material above the fracture stress and lead to cleavage/transgranular fracture. Ion-irradiated material does not allow direct measurement of fracture properties; therefore, tensile and impact tests on neutron-irradiated material will be conducted to resolve the question of irradiation embrittlement of V4Cr4Ti alloy at moderate temperatures.

\section{CONCLUSIONS}

1. Heavy-ion irradiation of bulk V-base alloys provide reasonable simulation of fast-neutron damage at moderate temperatures. Radiation-induced defect structures produced with $\mathrm{Ni}^{++}$and $\mathrm{V}^{+}$ions resembles those of fast-neutron-irradiated material at similar dose and temperature. The prevalent defects are point defect clusters and dislocation loops, which are clearly seen at 0.5 dpa and increase in size with further irradiation.

2. Fast neutron, single ion, and dual ion $\left(\mathrm{Ni}^{++}\right.$and $\left.\mathrm{He}^{+}\right)$irradiations did not cause formation of voids and/or gas bubbles at temperatures of $200-420^{\circ} \mathrm{C}$ hinting that the $\mathrm{V} 4 \mathrm{Cr} 4 \mathrm{Ti}$ alloy is resistant to swelling at least up to $10 \mathrm{dpa}$ fluence in this temperatures range.

3. It cannot be concluded at this time if the irradiation-induced structural changes, i.e., significantly higher density of defect clusters and dislocation loops, should facilitate brittle fracture. It should be noted that defect-denuded zones have developed and grain boundary precipitation have been promoted. These structural changes should make material more susceptible to intergranular fracture. Further work is in progress to investigate the susceptibility of V-base alloys to brittle fracture after irradiation in this temperature range.

\section{REFERENCES}

${ }^{1}$ R. E. Gold and D. L. Harrod, Int. Met. Rev. $5 / 6(1980) 232$

${ }^{2}$ B. A. Loomis and D. L. Smith, J. Nucl. Mater. 191-194 (1992) 84

${ }^{3}$ D. L. Smith, B. A. Loomis and D. R. Diercks, J. Nucl. Mater. 135 (1985) 125-139

${ }^{4}$ D. S. Geles, S. Ohnuki, and H, Takahashi, in Fusion Reactor Materials, Semiannual Prog. Report, DOE/ER0313/20, Oak Ridge National Laboratory, Oak Ridge, TN, (1996), 96-100

${ }^{5}$ H. M. Chung, L. J. Nowicki, and D. L. Smith, in Fusion Reactor Materials, Semiannual Prog. Report, DOE/ER0313/20, Oak Ridge National Laboratory, Oak Ridge, TN, (1996), 84-86

${ }^{6}$ A. F. Rowcliffe, in Fusion Reactor Materials, Semiannual Prog. Report, DOE/ER-0313/20, Oak Ridge National Laboratory, Oak Ridge, TN, (1996), 323-332

${ }^{7}$ C. Abromeit, J. Nucl. Mater. 216 (1994) 78-96

${ }^{8}$ B. A. Loomis, H. M. Chung, L. J. Nowicki, and D. L. Smith, J. Nucl. Mater. 212-215 (1994) 799-803

${ }^{9}$ H. M. Chung, H-C. Tsai, D. L. Smith, R. Peterson, C. Curtis, C. Wojcik, and R. Kinney, in Fusion Reactor Materials, Semiannual Prog. Report, DOE/ER-0313/17, Oak Ridge National Laboratory, Oak Ridge, TN, (1995), 178-182

${ }^{10} \mathrm{~J}$. F. Ziegler, TRIM-Transport of Ions in Materials, Version 92, Yorktown, NY, IBM Research.

${ }^{11}$ H-C. Tsai, R. V. Strain, A. G. Hins, H. M. Chung, L. J. Nowicki and D. L. Smith, in Fusion Reactor Materials, DOE/ER-0313/17, Oak Ridge National Laboratory, Oak Ridge, TN, (1995), 8-14

${ }^{12}$ A. van Veen, H. Eleveld, and M. Clement, J. Nucl. Mater. 212-215 (1994) 287

${ }_{113}^{13}$ H. Matsui, K. Kuji, M. Hasegawa, and A. Kimura, J. Nucl. Mater. 212-215 (1994) 784

${ }^{14}$ T. Shikama, S. Ishino, and Y. Mishima, J. Nucl. Mater. 69 (1977) 315

${ }^{15}$ A. I. Ryazanov, V. M. Manichev, and W. van Witzenburg, J. Nucl. Mater. 231 (1996) 304 